\title{
Significance of Laparoscopic D2 Gastrectomy: Reply to Letter
}

\author{
Hideki Kawamura
}

Published online: 19 April 2009

(C) Société Internationale de Chirurgie 2009

My co-authors and I are grateful for the interest in our article shown by Dr. Liakakos and colleagues. In it, we reported the safety and accuracy of D2 lymph node dissection-the standard operation for advanced gastric cancer in East Asia-in laparoscopy-assisted distal gastrectomy using early gastric cancer cases, as the first step in operating on advanced gastric cancer [1]. Liakakos et al. [2] make two suggestions and pose one question about our account of laparoscopic gastrectomy and lymph node dissection for gastric cancer. What follows is my response.

Their first suggestion is that a randomized control trial (RCT) is needed to test the benefit of laparoscopic gastrectomy. We believe the benefit is short-term quality of life after laparoscopic gastrectomy. However, because we do not have data from long-term follow-up for laparoscopic gastrectomy in treating advanced gastric cancer, we agree that a RCT is needed for the scientific verification of the survival benefit of the procedure.

Next, they ask about the efficacy of D2 lymph node dissection. The problems associated with D2 lymph node dissection were demonstrated in RCTs released in $1990 \mathrm{~s}$. Those RCTs concluded that D2 lymph node dissection was associated with a high postoperative morbidity rate and had no survival benefit [3-5]. However, two RCTs released in recent years, both of which were performed by well-trained and experienced surgeons, reported a low postoperative morbidity rate and better survival benefit in D2 lymph node dissection than in D1 lymph node dissection [6, 7]. A RCT performed by the Japan Clinical Oncology Group proved that there is no survival benefit from prophylactic D3 lymph

H. Kawamura $(\bowtie)$

Department of Surgery, JA Sapporo Kosei Hospital,

N3, E8, chuo-ku, Sapporo, Japan

e-mail: h.kawamura@ja-hokkaidoukouseiren.or.jp node dissection (para-aortic lymph node dissection), so we should aim to perform D2 lymph node dissection in cases of advanced gastric cancer if curative resection is possible [8].

Finally, Liakakos et al. suggest prophylactic gastrectomy for the genetically high-risk patient. We think this is an interesting idea, but there are associated ethical problems (gastrectomy for patients without cancer or possibility of other modalities). If the ethical questions can be resolved, laparoscopic gastrectomy would be the first recommended modality.

\section{References}

1. Kawamura H, Homma S, Yokota R et al (2008) Inspection of safety and accuracy of D2 lymph node dissection in laparoscopyassisted distal gastrectomy. World J Surg 32:2366-2370

2. Liakakos T, Patapis P, Charalambopoulos A et al (2009) Laparoscopic D2 gastrectomy: time for a randomized trial. World J Surg. doi:10.1007/s00268-009-9948-y

3. Robertson CS, Chung SCS, Woods SDS et al (1994) A prospective randomized trial comparing R1 subtotal gastrectomy with R3 total gastrectomy for antral cancer. Ann Surg 220:176-182

4. Cuschieri A, Weeden S, Fielding J et al (1999) Patient survival after D1 and D2 resection for gastric cancer: long-term results of the MRC randomized surgical trial. Surgical Co-operative Group. Br J Cancer 79:1522-1530

5. Hartgrink HH, van de Velde CJ, Putter H et al (2004) Extended lymph node dissection for gastric cancer: who may benefit? Final results of the randomized Dutch Gastric Cancer Group Trial. J Clin Oncol 22:2067-2077

6. Edwards P, Blackshaw GR, Lewis WG et al (2004) Prospective comparison of D1 vs modified D2 gastrectomy for carcinoma. Br J Cancer 90:1888-1892

7. Wu CW, Hsiung CA, Lo SS et al (2006) Nodal dissection for patients with gastric cancer: a randomised controlled trial. Lancet Oncol 7:309-315

8. Sano T, Sasako M, Yamamoto S et al (2004) Morbidity and mortality results from a prospective randomized controlled trial comparing D2 and extended para-aortic lymphadenectomy: Japan Clinical Oncology Group Study 9501. J Clin Oncol 22:2767-2773 